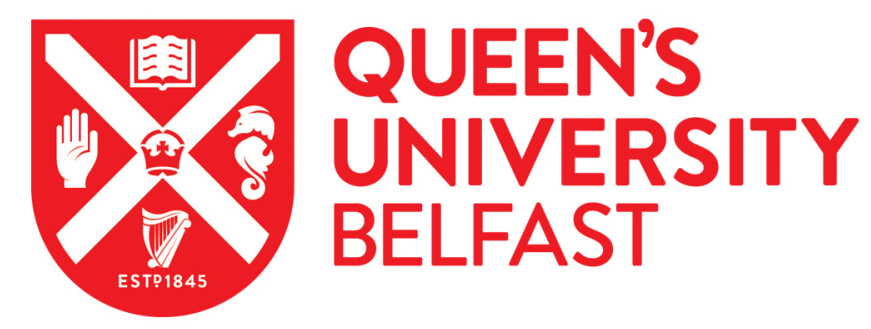

\title{
What can carcass-based assessments tell us about the lifetime welfare status of pigs?
}

Carroll, G. A., Boyle, L. A., Hanlon, A., Collins, L., Griffin, K., Friel, M., Armstrong, D., \& O'Connell, N. E. (2018). What can carcass-based assessments tell us about the lifetime welfare status of pigs? Livestock Science. https://doi.org/10.1016/j.livsci.2018.04.020

\section{Published in:}

Livestock Science

\section{Document Version:}

Peer reviewed version

Queen's University Belfast - Research Portal:

Link to publication record in Queen's University Belfast Research Portal

\section{Publisher rights}

(C) 2018 Elsevier B.V. All rights reserved.

This manuscript version is made available under the CC-BY-NC-ND 4.0 license http://creativecommons.org/licenses/by-nc-nd/4.0/,which permits distribution and reproduction for noncommercial purposes, provided the author and source are cited

\section{General rights}

Copyright for the publications made accessible via the Queen's University Belfast Research Portal is retained by the author(s) and / or other copyright owners and it is a condition of accessing these publications that users recognise and abide by the legal requirements associated with these rights.

Take down policy

The Research Portal is Queen's institutional repository that provides access to Queen's research output. Every effort has been made to ensure that content in the Research Portal does not infringe any person's rights, or applicable UK laws. If you discover content in the Research Portal that you believe breaches copyright or violates any law, please contact openaccess@qub.ac.uk. 
1 What can carcass-based assessments tell us about the lifetime welfare status of pigs?

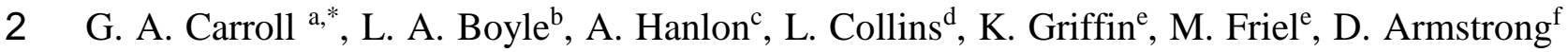
3 and N. E. O' Connell ${ }^{\mathrm{a}}$

4

$5 \quad$ a Institute for Global Food Security, Queens University Belfast, Northern Ireland Technology

6 Centre, Malone Road, Belfast BT9 5HN, UK

$7 \quad{ }^{b}$ Animal \& Grassland Research \& Innovation Centre, Teagasc Moorepark, Fermoy, Co Cork, $8 \quad$ Republic of Ireland

$9{ }^{c}$ School of Veterinary Medicine, University College Dublin, Belfield, Dublin 4, Republic of 10 Ireland

$11{ }^{d}$ Faculty of Biological Sciences, University of Leeds, Leeds, West Yorkshire, LS2 9JT, United 12 Kingdom

$13{ }^{e}$ School of Biological Sciences, Queens University Belfast, 97 Lisburn Road, Belfast BT9

$147 B L$, United Kingdom

$15{ }^{f}$ Agri-Food and Biosciences Institute Pig Unit, Large Park, Hillsborough, County Down 16 BT26 6DR, United Kingdom

$23{ }^{*}$ Corresponding author. Email address: gcarroll05@qub.ac.uk 
There is increasing interest in developing abattoir-based measures of farm animal welfare. It is important to understand the extent to which these measures reflect lifetime welfare status. The study aim was to determine whether lesions acquired during different production stages remain visible on the carcass, and the degree to which carcass-based measures may reflect broader health and welfare issues. 532 animals were assessed at 7, 9 and 10 weeks of age (early life, EL), and at 15 and 20 weeks of age (later life, LL) for tail lesions (TL), skin lesions (SL) and a number of health issues (HI) including lameness and coughing. Pigs were categorised according to when individual welfare issues occurred in the production process; 'early life' [EL], 'later life' [LL], 'whole life' [WL], or 'uninjured' (U) if showing no signs of a specific welfare issue on-farm. Following slaughter, carcasses were scored for tail length, tail lesions, and skin lesions, and cold carcass weights (CCW) were obtained. Generalised linear, ordinal logistic and binary logistic fixed model procedures were carried out to examine the ability of TL, SL and HI lifetime categories to predict carcass traits. Pigs with TL in EL, LL and WL had higher carcass tail lesion scores than U pigs $(\mathrm{P}<0.001)$. Pigs with TL in LL $(\mathrm{P}<0.05)$ and WL $(\mathrm{P}<0.001)$, but not in EL $(\mathrm{P}>0.05)$, also had shorter tails at slaughter than $\mathrm{U}$ pigs. In relation to TL scores, U pigs also had a higher cold carcass weight compared to LL and WL $(\mathrm{P}<0.001)$, but not EL pigs $(\mathrm{P}>0.05)$. Pigs with SL in EL, LL and WL had higher healed skin lesion scores on the carcass than U pigs $(\mathrm{P}<0.001)$. Health issues recorded during lifetime were not reflected in carcass measures used $(\mathrm{P}>0.05)$. The current study shows that tail lesions and skin lesions acquired at least 10 weeks before slaughter remain evident on the carcass and consequently, may be useful as tools to assist in determining the

47 lifetime welfare status of pigs. Low CCW was associated with tail lesions, supporting 48 previous research suggesting that tail lesions have a negative impact on growth performance 49 in pigs. 
51 Keywords: Pigs, animal welfare, abattoir, carcass, tail lesions

52

53 Funding: This work was supported by the Irish Department of Agriculture, Food and the

54 Marine [Research 479 Stimulus Fund (Grant 11/S/107)

55

56

57

58

59

60

61

62

63

64

65

66

67

68

69

70

71

72

73

74 


\section{Introduction}

77 Input-based measures of animal welfare, for example, recording of environmental factors such as stocking density or flooring type, are increasingly viewed as inadequate in reflecting the welfare of individual animals. In contrast, animal-based 'outcome' measures allow the effect of the environment on the animal to be directly assessed by examining how animals respond to, and are affected by, resource and management-based measures (Velarde and Dalmau, 2012, Otten et al., 2014). By directly recording the results of interactions between the environment and the animal, the true consequences that a particular management practise has on animal welfare can be measured (Welfare Quality, 2009). However, biosecurity issues associated with entering farms, and poor visibility associated with dim lighting, high stocking densities and dirty conditions, may hamper animal-based welfare assessments (Edwards et al., 1997, Velarde et al., 2005). Hence, the prospective benefits of using abattoir-based animal welfare assessments are increasingly recognised (Harley et al., 2012b). In the EU, all animals that are slaughtered for meat are subjected to a meat inspection (MI) process, with the primary aim of ensuring that meat is fit for human consumption. The

91 integration of outcome-based welfare measures into a pre-existing MI system would minimise costs (Harley et al., 2014), and allow a large number of animals from a variety of farms to be assessed in a relatively short period of time. Previous abattoir-based research has tended to

94 focus on assessing the effects of conditions at the abattoir on welfare-related carcass lesions. 95 For example, the presence of rough edges within the abattoir, excessive goad usage or intraspecific aggression has been associated with visible skin damage to pig carcasses (De Lama,

97 2012). Relatively little research has been conducted on the extent to which carcass-based assessments can inform us about the welfare status of pigs throughout their life. It is possible that lesions sustained early in the production cycle may not be detectable at the abattoir 
100 (Harley et al., 2012a), and the source of the damage may be difficult to ascertain (Grandin, 101 2007). Furthermore, only a limited number of welfare-related measures are suitable for postmortem assessment and the extent to which these measures reflect general health and welfare on-farm is unclear.

104 This study will examine the extent to which carcass-based measures of tail lesions, tail length, 105 fresh skin lesions, healed skin lesions, loin bruising and carcass weight in pigs reflect welfare 106 measurements recorded throughout the production cycle. In particular, the extent to which certain lesions acquired during different production stages remain visible on the carcass and the degree to which carcass-based measures may reflect broader health and welfare issues throughout life was assessed.

\section{Material and methods}

112 This non-invasive observational study complies with ARRIVE guidelines. The research was 113 conducted at the Agri-Food and Biosciences Institute, Hillsborough, Northern Ireland. Data 114 were collected between April 2013 and December 2014. Five hundred and thirty-two pigs 115 were assessed from a total of 720 pigs reared over 10 batches (each batch was reared at 116 approximately 6-week intervals). A number of pigs (188) were not included in the final data 117 set due to issues such as missing ear tags, being moved between pens or premature death. The 118 final sample size of 532 pigs (male: $\mathrm{n}=254$, female: $\mathrm{n}=278$ ) allows for $95 \%$ confidence with 119 a confidence interval of 0.039. This was calculated using the Statistics Service sample size 120 calculator (NSS, 2014), and involved entering a generic large pig population of 100,000 121 (Select Statistics, 2016) and an average proportion of pigs with skin lesions of 0.7 (Carroll et al., 2016). 
126 Pigs used in this experiment were PIC 337/Landrace mixed breed. Piglets had approximately $12750 \%$ of their tail length docked within 24 hours of birth, and were housed within standard 128 farrowing crate systems until weaning at 4 weeks of age. Pigs were provided with a 129 suspended wooden block as a form of enrichment in all pens during the pre-weaning, growing 130 and finishing periods.

131 During the growing phase ( $4-9.5$ weeks of age) pigs in each batch were housed in the 132 'weaning unit' within one of four groups of 18 pigs, which were balanced for sex and weight. Two of the pens were 'enriched' with deep straw bedding (replenished weekly) and a space 134 allowance of $0.62 \mathrm{~m}^{2}$ per pig. The other two pens were 'barren' and had no straw and a space 135 allowance of $0.41 \mathrm{~m}^{2}$ per pig. In both types of pens, floors were part slatted and constructed 136 from concrete.

137 At 9.5 weeks of age, each batch of pigs was transferred to a 'finishing unit'. At this stage, 138 approximately $90 \%$ of pigs were mixed into new groups that were balanced for sex and 139 weight, while remaining pigs stayed in their original groups. Pigs were housed in one of two 140 finishing houses in fully slatted pens within groups of either 10 (in house 1) or 20 (in house 2) 141 pigs. All pigs had an average space allowance of $0.64 \mathrm{~m}^{2}$ during this period. Pigs were slaughtered at 21 weeks of age.

\subsection{Data collection}

145 Each pig was assessed at 7 and 9 weeks of age (in the weaning unit) and at 10, 15 and 20 146 weeks of age (in the finishing unit). Assessments were carried out over two days in each 147 observation week.

148 Two trained observers entered each pen. Individual ear tag numbers were recorded and each 149 pig was given a unique spray mark to allow for individual identification. In order to carry out 
injury scoring, one observer slowly circled each pig and determined the scores that were to be

151

152

153

154

155

156

157

158

159

160

161

162

163

164

165

166

167

168

169

170

171

172

173

174

\section{7}

assigned. A second observer recorded the injury scores onto data sheets. Pigs were injury scored in random order. The animals were sometimes brought into the corridor of the barn to allow additional space for assessment of larger pigs.

\subsection{Lifetime welfare measures}

2.3.1. Skin lesions. Twelve areas of the body were assessed for aggression-related skin lesions, namely; the left ear, right ear, snout, left shoulder, right shoulder, front legs, back legs, left flank, right flank, left hindquarter, right hindquarter and back. A six point scoring system (0 to 5) (adapted from Calderón Díaz et al., 2014; Conte et al., 2012; Manciocco et al., 2011) was used (Table 1). Weekly scores were condensed into absent, mild, moderate and severe categories based on the following criteria; (0) absent: all regions scoring 0 , (1) mild: regions scoring 0 to 2 with a maximum of four regions scoring 3, (2) moderate: regions scoring 0 to 3 with a maximum of two regions scoring 4 or one region scoring 5 , (3) severe: regions scoring 0 to 3 , with three or more regions scoring 4 or two or more regions scoring 5 .

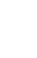

9

(1) 
175 Table 1 Skin lesion scoring method for pigs and abbreviations used for skin lesion groups

\section{Score Description}

$0 \quad$ No injuries

1 One small (approximately $2 \mathrm{~cm}$ ) superficial lesion (not penetrating the skin)

2 More than one small, superficial lesion or just one red (deeper than score 1) but still superficial lesion

3 One or several big ( 2 to $5 \mathrm{~cm}$ ) and deep (a lesion penetrating the skin) lesions. If deep; only one single lesion. If not so deep; several red lesions

$4 \quad$ One very big (> $5 \mathrm{~cm}$ ), deep and red lesion or many deep, red lesions

$5 \quad$ Many very big, deep and red lesions covering the skin area

Adapted from Manciocco et al., 2011; Conte et al., 2012; Calderón Díaz et al., 2014 Morrison's (2007) tail scoring system used by Harley et al. (2012b) (Fig. 1). 

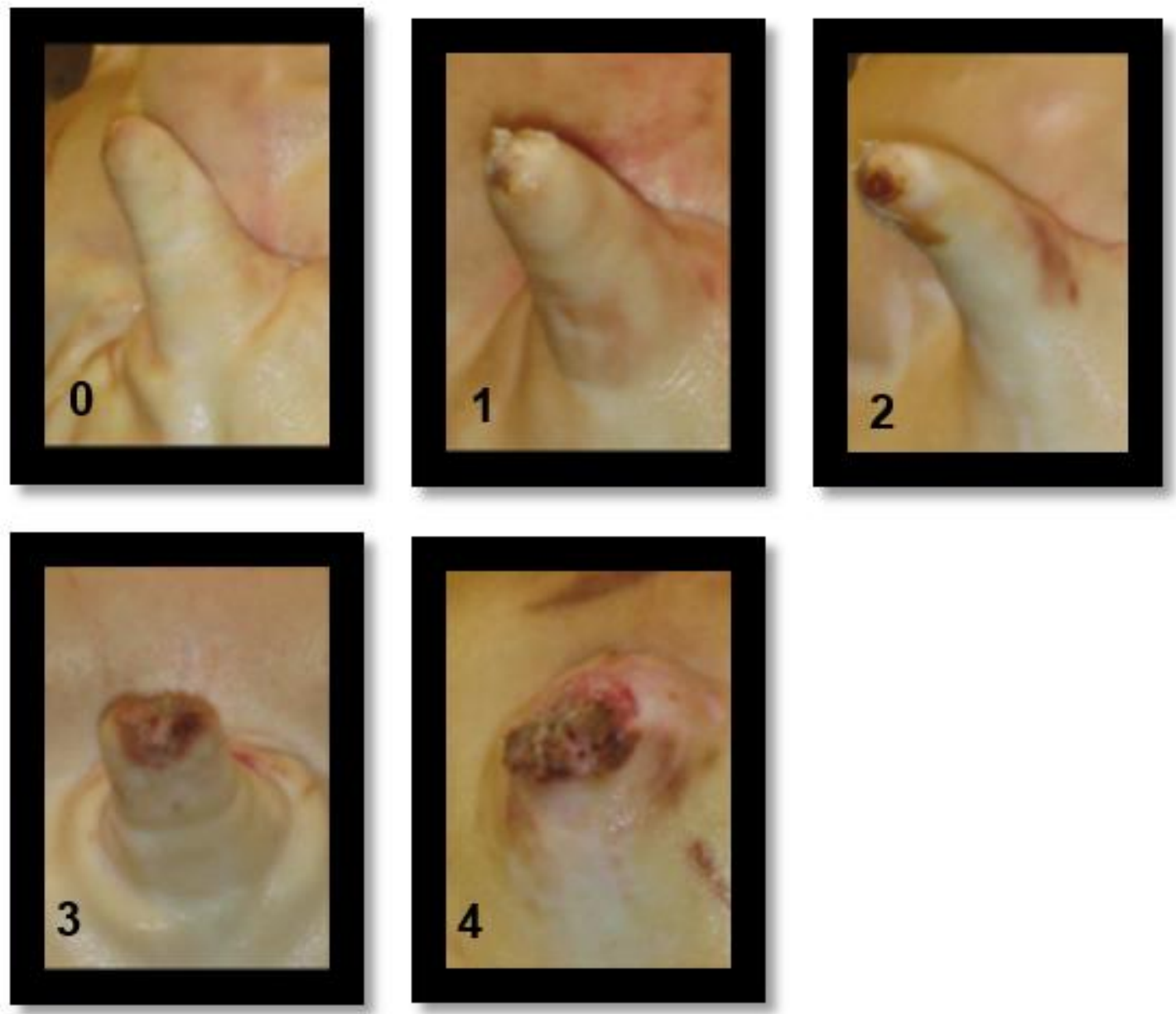

180

181 Fig. 1. Tail lesion scoring system. (0) no evidence of tail biting (1) mild/healed lesions (2)

182 evidence of chewing or puncture wounds, but no evidence of swelling (3) evidence of 183 chewing or puncture wounds, with swelling and signs of possible infection (4) partial or total 184 loss of tail 
2.3.3. Health issues. Each pig was assigned a score for a number of health issues namely; lameness, bursitis, hernias, rectal prolapse, scouring, coughing and aural hematomas, and body condition was assessed (Table 2). Lameness was assessed by observing each pig walking for several paces until the lameness status could be established. Any lying or sitting pigs were encouraged to stand and walk. Pigs unable to stand were left undisturbed and lameness scores recorded as 'missing'. In contrast to all other physical welfare measures, coughing was recorded on day 2 in order to allow adequate time for its detection. Each pen of 18-20 pigs was monitored for coughing for 20 minutes each, and the identity of any animal that coughed was recorded. In the finishing unit, a number of pigs were housed in groups of 10. In this case, two pens were assessed concurrently when directly adjacent to each other. Due to a low occurrence of many of the health issues, each animal was assigned a single 'presence' or 'absence' score for each health issue for analysis on the basis of whether it was evident in any of the observation periods. 
217 Table 2 Health issue scoring methods used in each pig welfare assessment $\dagger$

\begin{tabular}{|c|c|c|}
\hline Measure & Score & Description \\
\hline \multirow[t]{4}{*}{${ }^{1}$ Lameness } & 0 & Normal gait or difficulty in walking, but still using all legs \\
\hline & 1 & Severely lame, minimum weight-bearing on the affected limb \\
\hline & 2 & No weight-bearing on the affected limb \\
\hline & 3 & Not able to walk \\
\hline \multirow[t]{3}{*}{ *Bursitis } & 0 & No evidence of bursae/swelling \\
\hline & 1 & One or several small bursae on the same leg or one large bursa \\
\hline & 2 & $\begin{array}{l}\text { Several large bursae on the same leg, or one extremely large } \\
\text { bursa or any bursae that are eroded }\end{array}$ \\
\hline \multirow[t]{3}{*}{ \#Hernias } & 0 & No hernias \\
\hline & 1 & $\begin{array}{l}\text { Hernias or ruptures present, but the affected area is not bleeding, } \\
\text { not touching the floor and not affecting locomotion }\end{array}$ \\
\hline & 2 & $\begin{array}{l}\text { Bleeding lesions, hernias/ruptures and/or hernias/ruptures } \\
\text { touching the floor }\end{array}$ \\
\hline${ }^{1}$ Rectal & 0 & No internal tissue extruding from the rectum \\
\hline prolapse & 1 & Present - Internal tissue extruding from the rectum \\
\hline \multirow[t]{3}{*}{${ }^{1}$ Scouring } & 0 & No evidence of scouring \\
\hline & 1 & Possibly present by diarrhoea/staining around and below anus \\
\hline & 2 & Observed in the act of scouring \\
\hline \multirow[t]{2}{*}{ 1,2 Body con. } & 0 & Animal with a good body condition \\
\hline & 1 & Visible spine, hip and pin bones \\
\hline \multirow[t]{3}{*}{${ }^{1}$ Coughing } & 0 & Absent \\
\hline & 1 & Present (once) \\
\hline & 2 & Persistent (more than once) \\
\hline \multirow[t]{3}{*}{${ }^{3}$ Aural haem. } & 0 & No haematoma \\
\hline & 1 & Swelling of one ear \\
\hline & 2 & Swelling of both ears \\
\hline
\end{tabular}

$218 *$ Hock, knee and elbow scored separately

219 \# Umbilical and inguinal hernias scored separately

$220 \dagger$ Descriptions taken from Welfare Quality® protocol for pigs (2009)

$221{ }^{1}$ Adapted version of that outlined in the Welfare Quality ${ }^{\circledR}$ protocol for pigs (Welfare Quality ${ }^{\circledR}, 2009$ )

$222{ }^{2}$ Body con. = Body condition

$223{ }^{3}$ Aural haem. = Aural haematoma 
225 Pigs were categorised into one of four welfare categories for each analysis. Classification at 226 each life stage for tail lesions and health issues was based on the issues being present or 227 absent, regardless of severity. Due to the high frequency of mild skin lesions, skin lesion 228 classification was based on the presence or absence of moderate to severe skin lesions at each 229 life stage (Table 3). Uninjured (U) pigs for each welfare issue were those that showed no 230 evidence of that particular issue (tail lesions, moderate to severe skin lesions, or any health 231 issue) at any life stage. For example, with regard to tail lesion lifetime category, uninjured 232 pigs were those that showed no evidence of having tail lesions at any observation week (see 233 Table 3).

234

235 Table 3 Lifetime welfare classification criteria

\section{Category Description}

Early life (EL) Issue present on at least one occasion in weeks 7, 9 and 10 but not present in later life

Later Life (LL) Issue present on at least one occasion in weeks 15, 20 and above but not present in early life

Whole Life (WL) Issue present on at least one occasion in EL and at least one occasion in LL

Uninjured (C) Issue not present at any observation point 
241 One day prior to slaughter, each pig was given a unique slap mark and this was recorded

242 during the abattoir-based assessments. This allowed the lifetime welfare record for each pig to

243 be matched with the corresponding carcass.

244 On the day of slaughter, the pigs were loaded onto a two-deck lorry where they were mixed 245 with non-experimental animals from the same farm. Pigs were transported approximately 65

246 kilometres to the abattoir with a journey time of $\sim 1$ hour. The unique slap mark was also 247 recorded by meat inspectors, allowing cold carcass weight to be matched to each experimental 248 animal.

249 At slaughter, each pig was assessed by one researcher for skin lesions, tail lesions, tail length 250 and loin bruise severity. These measures were assessed immediately after the animals had 251 passed through the scalding and dehairing points on the slaughterline. This point of the 252 slaughter line has been deemed more appropriate for the detection of tail lesions, loin bruising 253 and severe skin lesions when compared to scoring of the unprocessed carcass (Carroll et al., 254 2016). Carcasses were sometimes scored for skin lesions in the chill room to allow sufficient 255 time for scoring of all carcass measures. However, assessment of the carcasses within the chill room often became logistically difficult and therefore seldom occurred.

2.5.1. Skin lesions. The skin lesion scoring system used for assessing live pigs was also used for scoring of skin lesions on the carcass with the following modifications; due to line speed, the 12 body regions scored were condensed into 3 body regions; the front (ears, snout, shoulders and front legs), the middle (flanks and back) and the rear (hindquarters and back legs). Furthermore, the 6-point scoring system was condensed into a 4-point scoring system, with score 1 and 2 being classified as 
mild, score 3 as moderate and scores 4 and 5 as severe. Finally, a distinction was made between fresh (red) and healed (non-red) lesions with each carcass being assigned scores for both fresh and older lesions simultaneously.

2.5.2. Tail lesions. The tail lesion scoring system used for scoring live pigs was also used for scoring of tail lesions on the carcass.

2.5.3. Tail length. A simplified tail scoring system was used that categorised tails are being either short $(\leq 5 \mathrm{~cm})$ or long $(>5 \mathrm{~cm})$.

2.5.4. Loin bruising. Loin bruising was scored using the system developed by Harley et al. (2014, Fig. 2). In addition, bruise colour was recorded using an adapted scoring system from Strappini et al. (2012) with the aim of determining the freshness of the bruise. The presence of red, blue, brown or yellow-orange bruising was noted.

278

279

280

281

282

283

284

285 

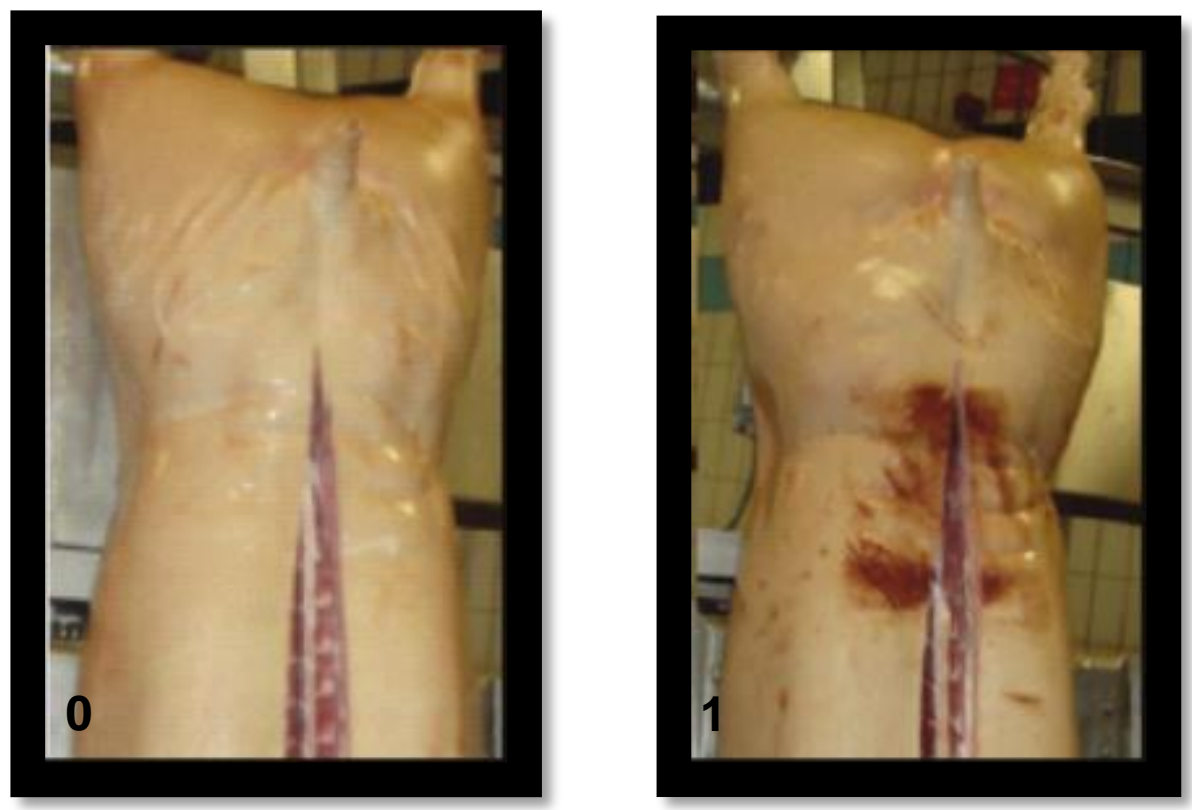

Fig. 2. Loin bruise scoring system. (0) absent, (1) present

2.5.5. Cold carcass weight. Information on individual cold carcass weights was collected after all experimental pigs were processed.

\subsection{Statistical analysis}

2.6.1. Descriptive statistics. The percentage of pigs with loin bruises of various colours was determined using descriptive statistics.

2.6.2. Fixed effects models. Depending on the measurement scale of the dependant variable, a number of binary logistic (nominal with two categories), ordinal logistic (ordinal) and generalised linear (ratio) fixed model procedures were carried out to examine the contribution of predictor variables 'Skin lesion life category', 'Tail lesion life category' and 'Health issue life category' in explaining the following dependant variables; healed carcass skin lesion score, fresh carcass skin lesion score, carcass tail lesion score, carcass tail length, the presence/absence 
(P/A) of loin bruising and cold carcass weight. Due to an overall low incidence of individual health issues, it was necessary to condense all health issues into one variable for analysis.

All statistical analyses were carried out using SPSS version 20.

309

310

311

\section{Results}

312 The prevalence of health and welfare issues at each observation week during the lifetime of 313 the animal is presented in Table 4.

314

315

3.1. Associations between carcass measures (in italics) and lifetime welfare indicators

316

317

3.1.1. Loin bruising. 'Skin lesion life category', 'Tail lesion life category' and 'Health issue life category' did not predict carcass loin bruising $(\mathrm{P}>0.05)$. Loin bruises were brown $(76 \%)$ or red $(24 \%)$. No blue or yellow-orange bruising was recorded.

320

321

322

323

324

325

326

327

328

329 
330 Table 4. Prevalence of health and welfare issues in pigs from 7 to 20 weeks of age

\begin{tabular}{|c|c|c|c|c|c|}
\hline \multirow[t]{2}{*}{ Variables measured } & \multicolumn{2}{|c|}{ Early Life (EL) } & \multicolumn{3}{|c|}{ Later Life (LL) } \\
\hline & \multicolumn{5}{|c|}{ Week } \\
\hline & 7 & 9 & 10 & 15 & 20 \\
\hline \multicolumn{6}{|l|}{ Tail lesions (\%) } \\
\hline Absent & 94.2 & 92.4 & 90.6 & 90.3 & 77.3 \\
\hline Mild & 5.8 & 7.6 & 8.8 & 9.1 & 13 \\
\hline Moderate & 0 & 0 & 0 & 0 & 6.3 \\
\hline Severe & 0 & 0 & 0.6 & 0.6 & 3.4 \\
\hline \multicolumn{6}{|l|}{ Skin lesions (\%) } \\
\hline Absent & 0 & 0 & 4.2 & 4 & 4.8 \\
\hline Mild & 99.7 & 100 & 66.9 & 86.9 & 84.8 \\
\hline Moderate & 0.3 & 0 & 14.6 & 5.7 & 9.3 \\
\hline Severe & 0 & 0 & 14.3 & 3.4 & 1.1 \\
\hline \multicolumn{6}{|l|}{ Health Issues (\%) } \\
\hline Lameness & 0.8 & 2.6 & 11.8 & 11.0 & 15.1 \\
\hline Bursitis & 0.9 & 2.6 & 2.7 & 8.7 & 7.0 \\
\hline Hernias & 0.0 & 0.3 & 0.0 & 0.5 & 1.5 \\
\hline Rectal prolapse & 0.0 & 0.0 & 0.0 & 0.0 & 0.0 \\
\hline Poor body condition & 0.5 & 0.3 & 0.0 & 0.3 & 0.0 \\
\hline Cough & 3.3 & 1.5 & 4.6 & 13.2 & 12.5 \\
\hline Scouring & 0.3 & 0.3 & 0.7 & 0.8 & 0.4 \\
\hline Aural hematoma & 1.6 & 0.4 & 0.0 & 0.0 & 0.0 \\
\hline Health Issue cumulative \% & 8.3 & 10.6 & 22.5 & 43.2 & 43.5 \\
\hline
\end{tabular}


3.1.2. Tail lesions. 'Skin lesion life category' and 'Health issue life category' did not predict carcass tail lesion score $(\mathrm{P}>0.05)$. The overall effect of 'Tail lesion $\dagger \quad \mathrm{P}<0.001 \quad \mathrm{P}<0.001 \quad \mathrm{P}<0.001$ lesion lifetime category significantly predicted carcass tail lesion score with uninjured (U) pigs having significantly lower carcass tail lesion scores compared to pigs with tail lesions in EL $(\mathrm{P}<0.001)$, LL $(\mathrm{P}<0.001)$ and $\mathrm{WL}(\mathrm{P}<0.001)$

(Fig. 3).

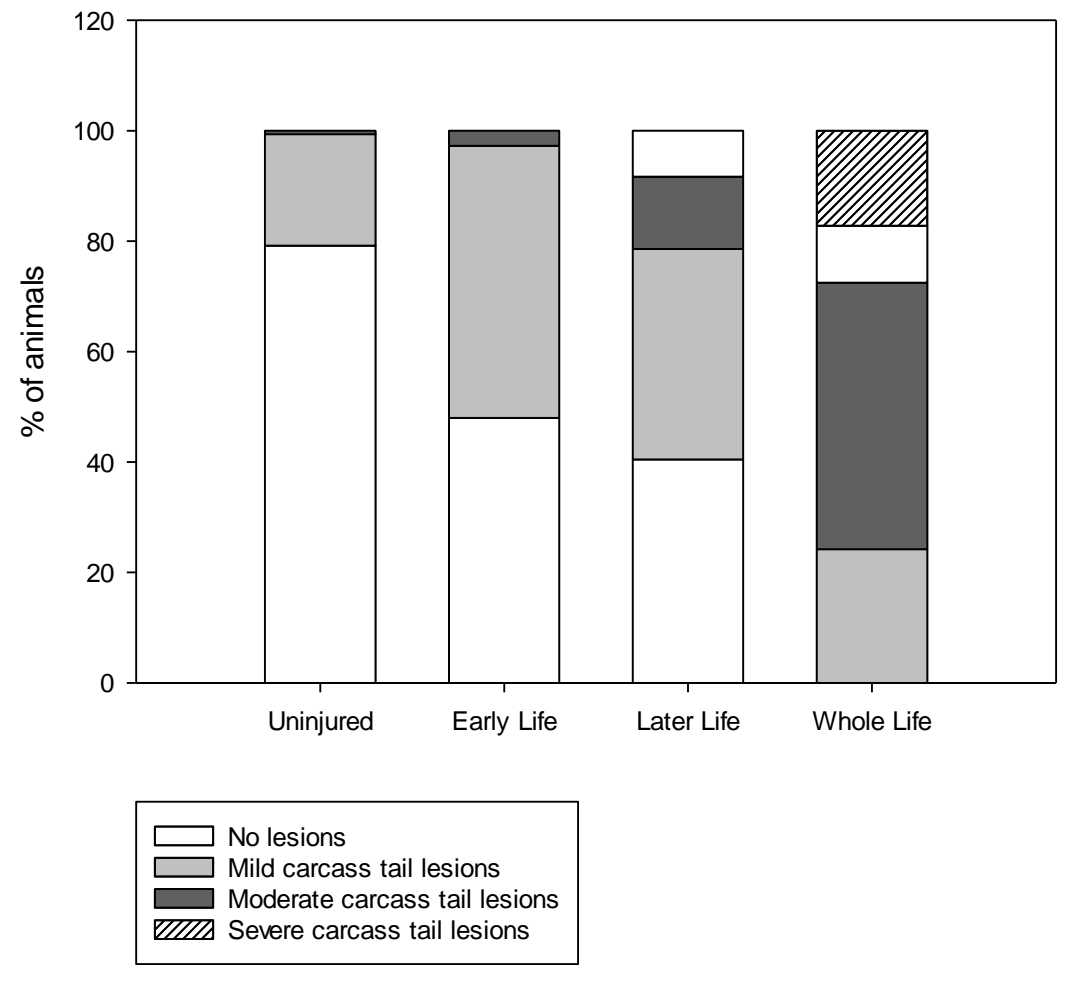

Fig. 3. The severity of carcass tail lesions for each Tail Lesion life category $\dagger=$ category that was compared to all other conditions in post-hoc analysis

3.1.3. Tail length. 'SL life category' and 'HI life category' did not predict carcass tail length $(\mathrm{P}>0.05)$. The overall effect of tail lesion lifetime category was significant (Wald3 = 29.96, $\mathrm{P}<0.001)$. Specifically, Uninjured pigs had full docked length tails (99\% prevalence) more often than LL pigs (87\% prevalence, $\mathrm{P}<0.05)$ and 
WL pigs $(74 \%$ prevalence, $\mathrm{P}<0.001)$, but not EL pigs $(99 \%$ prevalence, $\mathrm{P}>$ $0.05)$.

3.1.4. Healed skin lesions. 'Tail lesion life category' and 'Health issue life category' did not predict carcass healed skin lesion score $(\mathrm{P}>0.05)$. The overall effect of 'Skin lesion lifetime category' was significant ( $\left.\mathrm{Wald}_{3}=78.87, \mathrm{P}<0.001\right)$. Specifically, skin lesion lifetime category significantly predicted carcass healed skin lesion score with U pigs having significantly lower healed skin lesion scores on the carcass compared to EL ( $\mathrm{P}<0.001)$, LL $(\mathrm{P}<0.001)$ and WL pigs $(\mathrm{P}<0.001)$ (see Fig. 4).

356

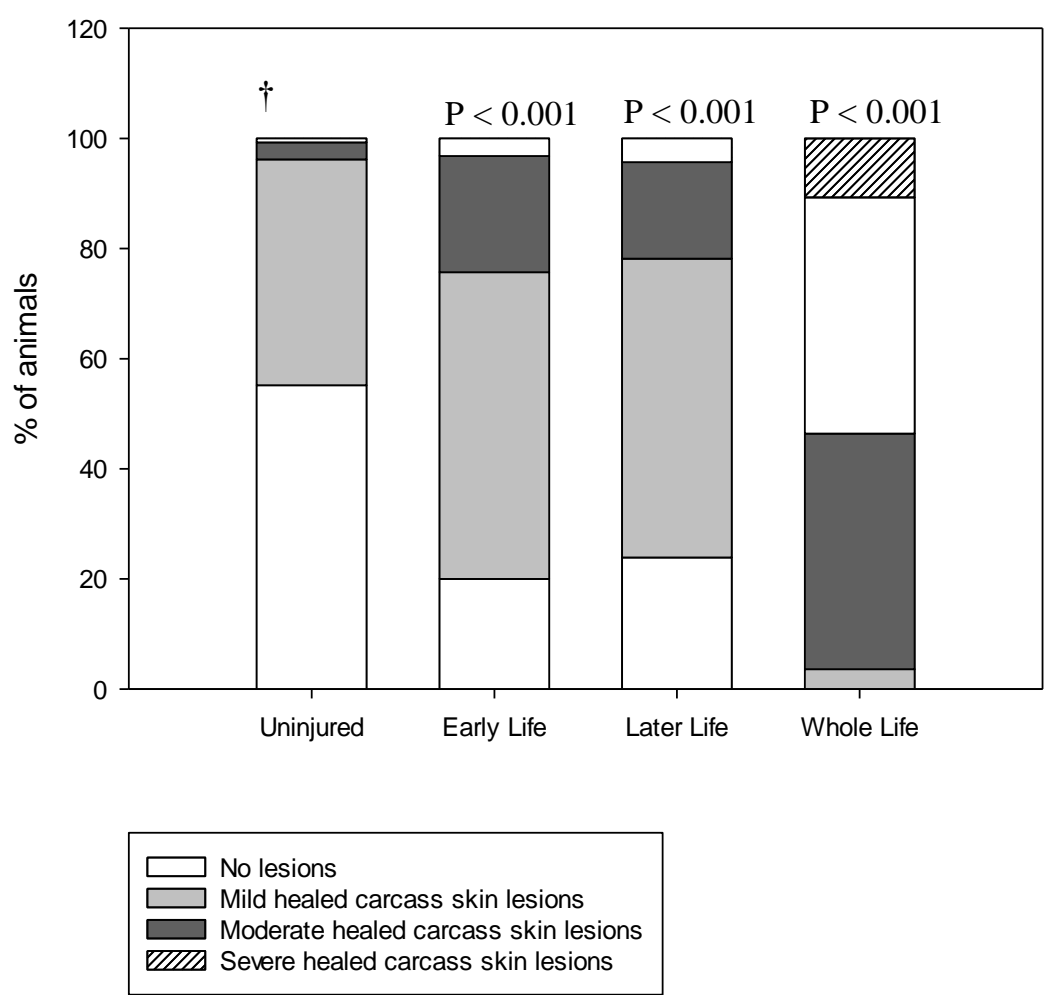

359 Fig. 4. The severity of healed carcass skin lesions for each Skin Lesion life category 
3.1.5. Fresh skin lesions. 'Tail lesion life category', 'Skin lesion life category' and 'Health issue life category' did not predict carcass fresh skin lesion scores $(\mathrm{P}>$ $0.05)$.

3.1.6. Cold carcass weight. 'Skin lesion life category' and 'Health issue life category' did not predict cold carcass weight $(\mathrm{P}>0.05)$. The overall effect of 'Tail lesion lifetime category' was significant $(\mathrm{F}=3.89, \mathrm{P}=0.010)$. Specifically, 'Tail lesion lifetime category significantly predicted cold carcass weight with $\mathrm{U}$ pigs having significantly higher cold carcass weight compared to LL and WL $(\mathrm{P}<0.05)$, but not EL pigs $(\mathrm{P}>0.05$, see fig. 5).

372

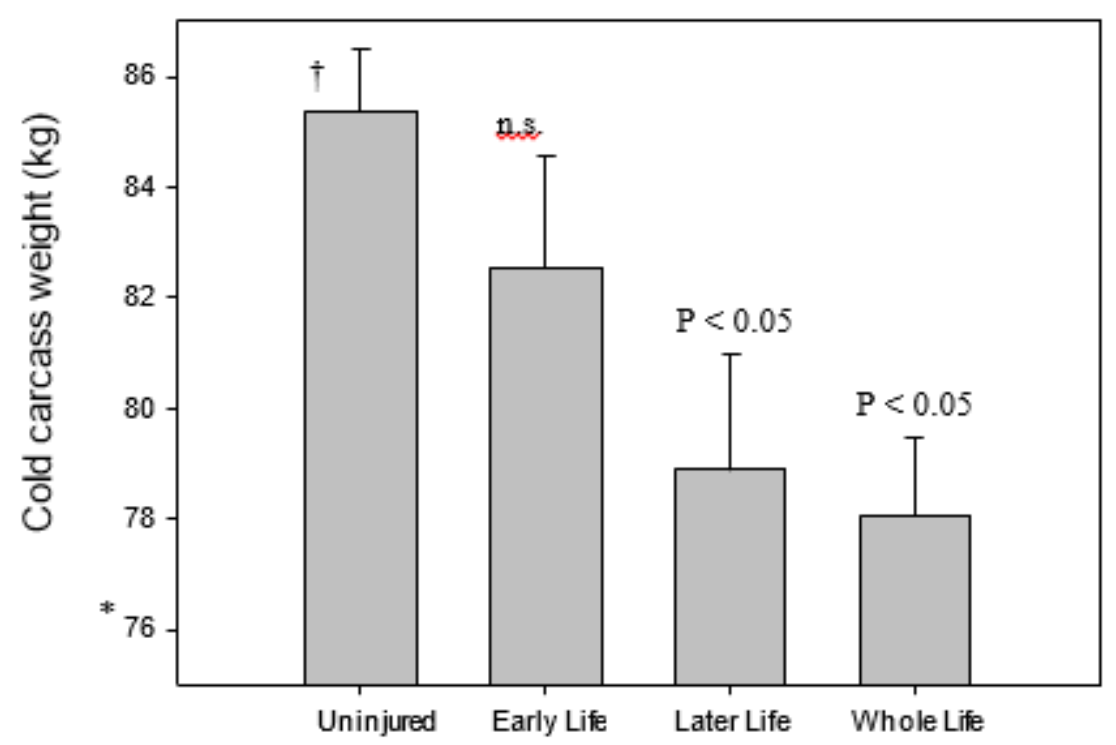

374 Fig. 5. Mean cold carcass weight $(\mathrm{kg})$ for each Tail Lesion life category

$375 \dagger=$ category that was compared to all other conditions in post-hoc analysis

$376 *=$ carcass weights start at $76 \mathrm{~kg}$ 
379 It is being increasingly recognised that it is possible to assess welfare issues that have occured 380 on farm, at the abattoir. In a recent review of the topic, Grandin (2017) concluded that 381 conditions such as lameness, necrotic prolapses, neglect injuries and shoulder sores, recorded 382 at the abattoir, could indicate welfare problems on the farm of origin. The potential of 383 abattoir-based assessments in indicating on-farm welfare is being considered in an ever384 increasing variety of species. For example, assessment of broiler chicken welfare has often 385 relied on post-mortem assessments (Roberts et al., 2012), and there is an increasing body of research focusing on post-mortem assessments in pigs (e.g. Harley et al., 2014; 2012a; 2012b; 387 Texeira et al., 2016). In addition, Llonch et al. (2015) recently identified a number of welfare 388 measures suitable for scoring post-mortem in sheep, including body cleanliness, carcass 389 bruising, skin lesions and skin irritation. However, despite the increased interest in developing 390 abattoir-based welfare measures, there is a lack of information on the ability of such measures 391 to detect welfare issues occurring at various stages throughout production. For example, it 392 may be that only recently sustained damage remains visible.

393 A handful of previous studies have aimed to specifically compare on-farm environmental, 394 husbandry and animal-based characteristics with carcass-based measures. For example, Allain 395 et al. (2009) found that deep footpad lesions and black hock burn on broiler chicken carcasses were associated with the presence of degraded litter on-farm, while carcass breast blisters and 397 scratches were associated with high on-farm stocking density. In contrast to this, Knage398 Rasmussen et al. (2015) found that meat inspection records were unable to predict a farm399 based welfare index score for sows that was created based on a number of welfare measures, 400 including measures of lameness, bursitis and behaviour. However, Allain et al. (2009) 401 obtained input-based information about on-farm welfare (e.g. stocking density) rather than 402 animal-based information. In addition, information on the farm characteristics in this study 
was reported by farmers via questionnaire. Therefore, these factors were not directly

404 measured and may provide only a snapshot of the conditon on-farm. Similarly, Knage405 Rasmussen et al. (2015) carried out on-farm assessments over one day, as opposed to 406 collection of the meat inspection data, which was collected over a longer period of time. The 407 farm-based measures collected in these studies may therefore have been unrepresentative of 408 the animals true health and welfare status during this time.

409 Recently, van Staaveren (2017) examined the extent to which carcass tail lesion and skin 410 lesion prevalence reflected animal welfare problems in pigs on-farm. Thirty-one Irish farms

411 were visited and six pens of pigs per farm, at varying production stages, were assessed.

412 Welfare issues, including tail lesions, lameness, bursitis, body condition and skin lesions, 413 were assessed during a 10-minute welfare assessment period. One batch of pigs from each 414 participant farm was then assessed post-mortem for skin lesions and tail lesions. van 415 Staaveren (2017) found that a proportion of the variance in poor body condition, bursitis and 416 severe tail lesion prevalence at different production stages was predicted by carcass tail and 417 skin lesion prevalence. This suggests that carcass lesions recorded at MI may indeed be useful 418 for assessing on-farm welfare. However, similar to Knage-Rasmussen et al. (2015), farm 419 welfare assessments were carried out over one day per farm. In addition, the animals assessed 420 post-mortem were unlikely to be those assessed on the farm. To the authors' knowledge, the 421 current study is the first in any farm animal species to compare animal-based measures of 422 health and welfare, repeated over much of the animals' lifetime, to animal-based measures 423 taken from the carcass of the same animals. 
428 The study findings suggest that tail damage sustained over the lifetime of pigs remains visible

429 on the carcass. Even tail lesions that were only visible in early life on the farm were visible on 430 the carcass up to 14 weeks after they had been acquired. The binary tail scoring system, which 431 distinguished short tails from long tails (in relation to docked length) was successful in 432 discriminating pigs that had tail lesions in 'Later Life' and 'Whole Life', but could not 433 distinguish between pigs that had tail lesions in Early Life from Uninjured pigs. Moderate and 434 severe tail lesions were only seen from week 10 onwards (see Table 4) and no pigs had 435 moderate or severe tail lesions in Early Life only. This suggests that the simplified tail scoring 436 method may only be suited to detecting more severe tail lesions. This is logical as mild tail 437 lesions (scores 1 and 2) do not result in shortening of the tail length (see Fig. 1). The 438 simplified tail scoring system used in the current study was based on assessing tail length in 439 relation to the docked length (approximately $50 \%$ of the original tail length). This scoring 440 system would need to be adjusted when assessing pigs with intact tails. For example, evidence 441 suggests that while over $90 \%$ of Irish pigs are tail docked, less than $10 \%$ of Finnish pigs 442 undergo this procedure (Sutherland and Tucker, 2011). Therefore, a tail length of greater than $4435 \mathrm{~cm}$ could indicate tail lesions in a pig with an intact tail. Similarly, the scoring system that 444 should be used will vary when pigs are either short-docked, where less than $1.5 \mathrm{~cm}$ of the tail 445 is remaining, or 'tipped', where only the very top of the tail is removed (Hunter et al., 2001).

446 Although tail lesions are thought to reflect several husbandry and environmental factors on447 farm (EFSA, 2007), they were not linked to any individual health issues during the lifetime of 448 pigs in the current study. Mullan et al. (2009) found very few statistically significant 449 associations between various on-farm health and welfare issues such as tail lesions, lameness 450 and bursitis, and concluded that no on-farm welfare measure can be reliably replaced by 
another. Similar to this, the current study findings suggest that tail lesions on the carcass

452 cannot be used as an indirect indicator of the presence of health issues on-farm.

455 The findings of this study demonstrate that skin lesions occurring both in early and later life remain visible on the carcass in the form of healed (non-red) skin lesions. Pigs with moderate

457 to severe skin lesions over the 'Whole Life' had the most serious skin lesions on the carcass.

458 Although skin lesions acquired in 'Early Life' had a longer time available for healing, lesions 459 acquired at this stage were slightly more serious than those acquired in 'Later Life' (Fig. 5).

460 This is likely due to the fact that 'Early Life' was classified as weeks 7, 9 and 10. At week 10, 461 unfamiliar pigs were mixed into finishing pens. High levels of aggression can be seen at this 462 stage of production (Fàbrega et al., 2013). Consequently, it is likely that the most severe skin 463 damage was acquired at this stage. These findings suggest that skin damage occurring 11 464 weeks prior to slaughter remains visible on the carcass. However, although moderate to 465 severe when initially acquired, the lesions appeared as mild on the carcass. Therefore, if on466 farm aggression levels are to be reflected, a sensitive skin lesion scoring system is required.

467 In contrast to tail lesions, which tend to be reliable indicators of welfare issues on-farm, skin 468 lesions are frequently acquired during the marketing process. For example, aggressive 469 interactions can occur due to mixing of unfamiliar animals during transportation and holding 470 within the lairage (Guàrdia et al., 2009; Faucitano, 2010). The fact that fresh skin lesions were 471 not associated with skin lesions acquired on-farm suggests that these lesions are indicative of 472 welfare issues encountered during the marketing process. 
476 Harley et al. (2012b) found that approximately 1\% of Irish pigs are either partially or entirely

477 condemned at slaughter. Given the sample size of 532 animals in the current study, it would 478 not have been possible to try to robustly link carcass condemnation records from our 479 experimental pigs with welfare-related measures recorded throughout their lifetime. We 480 were, however, interested in the extent to which our other carcass-based measures may have 481 reflected health status recorded during lifetime assessments. For example, previous studies 482 have linked tail lesions with a number of health conditions detected at condemnation of 483 viscera, including pleurisy, pneumonia and pleuropneumonia (Teixeira et al., 2016). In 484 addition, stress associated with receiving high levels of aggression may compromise the 485 immune system (Desire et al., 2016) making animals more susceptible to disease. Therefore, 486 we may have expected to see a relationship between skin lesions scores and lifetime health 487 status. The lack of relationships shown could perhaps have reflected the relatively low 488 numbers of animals detected with health issues during our study, which, in turn, could reflect 489 the fact that these pigs were housed in experimental facilities. It is also possible that the 490 grouping of health conditions recorded during lifetime into one overall category may have 491 masked any potential relationships between carcass measures and specific health conditions. 492 Further research, utilising a larger sample size, is needed to determine whether health issues 493 on farm are indeed linked to carcass-based welfare indicators in any meaningful way.

\subsection{Carcass loin bruising}

496 The lack of association between loin bruising and lifetime welfare measures suggests that this 497 issue may not be a good indicator of on-farm welfare. However, it may also be due to the fact that loin bruising was not directly comparable with any on-farm measure. In contrast to tail 
lesions and skin lesions, loin bruising is not easily visible on the live animal (Carroll et al.,

500 2016). Therefore, assessing levels of bruising on farm is not feasible. It can therefore only be 501 concluded that loin bruising on the carcass does not appear to be related to levels of 502 aggression, tail biting or the general health of pigs on the farm. It is possible that loin bruising 503 is a problem that occurs during the marketing process. For example, sharp edges and improper 504 handling at abattoirs in cattle can result in carcass bruising (Grandin, 2007), and it is possible 505 that factors such as these could explain loin bruises seen on pig carcasses. However, most loin 506 bruises recorded in the current study were brown in colour, suggesting that the damage is 507 older (Merck et al., 2012). Further research is needed to uncover the exact cause of loin 508 bruising before its inclusion as part of an abattoir-based welfare assessment system can be 509 recommended.

\subsection{Cold carcass weight}

512 Skin lesions and health issues present on-farm were not associated with individual carcass 513 weights. However, the findings suggest that lower carcass weights may be indicative of tail

514 biting issues on-farm with pigs that were tail bitten in 'Later Life' and 'Whole Life' having 515 significantly lower carcass weights than uninjured animals. This finding is consistent with 516 previous studies which found a negative association between tail lesions and performance 517 parameters including average daily weight gain, feed conversion ratio and slaughter weight 518 (Harley et al., 2012b; Kritas and Morrison, 2007; Rydhmer et al., 2006; Sinisalo et al., 2012;

519 Wallgren and Lindahl, 1996). Poor health may result in poorer growth (Taylor et al., 2012), 520 and, as tail lesions are often associated with secondary infections (Kritas and Morrison, 2007), 521 this may explain the lower carcass weights. It is also possible that bitten pigs decrease their 
522 food intake due to an unwillingness to expose the tail to further biting when at the feeder

523 (Munsterhjelm et al., 2015).

525 The findings of this study suggest that tail lesions and skin lesions, acquired in early and later

526 life, remain visible post-mortem. Therefore, carcass-based assessments of these lesion types 527 reflect lifetime welfare status, rather than merely reflecting welfare in the immediate pre528 slaughter period. Overall, the current study shows that it is possible to detect tail and skin 529 lesions acquired by pigs in early life (during the growing period) on their carcass when they 530 are slaughtered at a standard commercial age. These measures could therefore form part of 531 meat inspection, and indeed, abattoir-based quality assurance schemes aimed at capturing 532 longer-term information on the welfare status of pigs. Additional studies conducted on 533 commercial farms are needed to validate these initial findings, and to more fully explore the 534 links between these carcass-based measures and health and welfare measures recorded during 535 lifetime.

\section{Acknowledgements}

539 The authors thank the AFBI farm and abattoir staff for their help and assistance with animal

540 handling and provision of farm records. 


\section{References}

Allain, V., Mirabito, L., Arnould, C., Colas, M., Le Bouquin, S., Lupo, C., Michel, V., 2009. Skin lesions in broiler chickens measured at the slaughterhouse: relationships between lesions and between their prevalence and rearing factors. Br. Poult. Sci. 50, 407-417.

Calderón Díaz, J.A.., Fahey, A.G., Boyle, L.A., 2014. Effects of gestation housing system and floor type during lactation on locomotory ability; body, limb, and claw lesions and lying-down behavior of lactating sows. J. Anim. Sci. 92, 1673-1683.

Carroll, G.A., Boyle, L.A., Teixeira, D.L., Staaveren, N. Van, Hanlon, A., O' Connell, N.E., 2016. Effects of scalding and dehairing of pig carcasses at abattoirs on the visibility of welfare-related lesions. Anim. 10(3), $460-467$.

Chulayo, A.Y., Muchenje, V., 2015. A balanced perspective on animal welfare for improved meat and meat products. S. Afr. J. Anim. Sci. 45, 452 - 469.

Conte, S., Lawlor, P.G., O'Connell, N., Boyle, L. A., 2012. Effect of split marketing on the welfare, performance, and carcass traits of finishing pigs. J. Anim. Sci. 90, $373-80$.

Desire, S., Turner, S. P., D’Eath, R. B., Doeschl-Wilson, A. B., Lewis, C. R.G. and Roehe, R., 2016. Prediction of reduction in aggressive behaviour of growing pigs using skin lesion traits as selection criteria. Anim. 10, 1243-1253.

Edwards, D.S., Johnston, A.M., Mead, G.C., 1997. Meat inspection: an overview of present practices and future trends. Vet. J. London Engl. 154, 135-147.

European Food Safety Authority (EFSA) 2007. Animal health and welfare in fattening pigs in relation to housing and husbandry. Th. EFSA. J. 564, 1-14.

Fàbrega, E., Puigvert, X., Soler, J., Tibau, J., Dalmau, A., 2013. Effect of on farm mixing and slaughter strategy on behaviour, welfare and productivity in Duroc finished entire male pigs. Appl. Anim. Behav. Sci. 143, 31-39.

Faucitano, L., 2010. Invited review: Effects of lairage and slaughter conditions on animal welfare and pork quality. Can. J. Anim. Sci. 90, 461-469.

Grandin, T., 2017. On-farm conditions that compromise animal welfare that can be monitored at the slaughter plant. Meat. Sci. 132, 52-58.

Grandin, T., 2007. How to Track Down the Cause of Bruising. http://grandin.com/references/cause.bruising.html (accessed 01.03.15). 
Guàrdia, M.D., Estany, J., Balasch, S., Oliver, M.A, Gispert, M., Diestre, A., 2009. Risk assessment of skin damage due to pre-slaughter conditions and RYR1 gene in pigs. Meat Sci. 81, 745-51.

Harley, S., Boyle, L., O’Connell, N., More, S., Teixeira, D., Hanlon, a, 2014. Docking the value of pigmeat? Prevalence and financial implications of welfare lesions in Irish slaughter pigs. Anim. Welf. 23, 275-285.

Harley, S., More, S., Boyle, L., O’Connell, N.E., Hanlon, A., 2012a. Good animal welfare makes economic sense: potential of pig abattoir meat inspection as a welfare surveillance tool. Ir. Vet. J. 65, 11.

Harley, S., More, S.J., O’Connell, N.E.., Hanlon, A., Teixeira, D., Boyle, L., 2012b. Paper Evaluating the prevalence of tail biting and carcase condemnations in slaughter pigs in the Republic and Northern Ireland, and the potential of abattoir meat inspection as a welfare surveillance tool. Vet. Rec. 171, $621-621$.

Huey, R.J., 1996. Incidence, location and interrelationships between the sites of abscesses recorded in pigs at a bacon factory in Northern Ireland. Vet Rec. 138, 511-514.

Hunter, E. J., Jones, T. A., Guise, H. J., Penny, R. H. and Hoste, S. 2001. The relationship between tail biting in pigs, docking procedure and other management practices. Vet. J. $161,72-9$.

Knage-Rasmussen, K.M., Rousing, T., Sørensen, J.T., Houe, H., 2015. Assessing animal welfare in sow herds using data on meat inspection, medication and mortality. Anim. 9, 509 - 515.

Kritas, S.K., Morrison, R.B., 2007. Relationships between tail biting in pigs and disease lesions and condemnations at slaughter. Vet. Rec. 160, 149-152.

Llonch, P., King, E.M., Clarke, K.A., Downes, J.M., Green, L.E., 2015. A systematic review of animal based indicators of sheep welfare on farm, at market and during transport, and qualitative appraisal of their validity and feasibility for use in UK abattoirs. Vet J. 206, 289-9.

Manciocco, A., Sensi, M., Moscati, L., Battistacci, L., Laviola, G., Brambilla, G., Vitale, A., Alleva, E., 2011. Longitudinal effects of environmental enrichment on behaviour and physiology of pigs reared on an intensive-stock farm. Ital. J. Anim. Sci. 10, 224232 .

Merck, M.D., Miller, D.M., Maiorka, P.C., 2012. CSI in Veterinary Forensics: Animal Cruelty Investigations. John Wiley \& Sons, Inc., New Jersey, pp. 37-68.

Miranda de la Lama, G.C., Villarroel, M., María, G.A., 2014. Livestock transport from the perspective of the pre-slaughter logistic chain : a review. Meat Sci. 98, 9-20. 
615 Miranda de la Lama, G.C., Leyva, I.G., Barreras-serrano, A., Pérez-linares, C., Sánchez616 lópez, E., María, G.A., Figueroa-saavedra, F., 2012. Assessment of cattle welfare at a 617 commercial slaughter plant in the northwest of Mexico. Trop. Anim. Health. Prod. 44; 497-504.

619 Mullan, S., Browne, W.J., Edwards, S.A., Butterworth, A., Whay, H.R., Main, D.C.J., 2009.

620

621

622

623

624

625

626

627

628

629

630

631

632

633

634

635

636

637

638

639

640

641

642

643

644

645

646

647

648

649 The effect of sampling strategy on the estimated prevalence of welfare outcome measures on finishing pig farms. Appl. Anim. Behav. Sci. 119, 39-48.

Munsterhjelm, C., Heinonen, M., Valros, A., 2015. Effects of clinical lameness and tail biting lesions on voluntary feed intake in growing pigs. Livest. Sci. 181, 210-219.

National Statistical Service, 2014. Sample size calculator examples. http://www.nss.gov.au/ (accessed 13.03.14).

Otten, N.D., Nielsen, L.R., Thomsen, P.T., Houe, H., 2014. Register-based predictors of violations of animal welfare legislation in dairy herds. Anim. 8, 1963-1970.

Roberts, S.J., Cain, R., Dawkins, M.S., 2012. Prediction of welfare outcomes for broiler chickens using Bayesian regression on continuous optical flow data. J. R. Soc. Interface. $\quad 9,3436-3443$.

Rydhmer, L., Zamaratskaia, G., Andersson, H.K., Algers, B., Guillemet, R., Lundström, K., 2006. Aggressive and sexual behaviour of growing and finishing pigs reared in groups, without castration. Acta Agric. Scand. Anim. Sci. 56, 109-119.

Select Statistics, 2016. Population Proportion - Sample Size. https://selectstatistics.co.uk/calculators/sample-size-calculator-population-proportion/ (accessed 04.08.16).

Sinisalo, A., Niemi, J.K., Heinonen, M., Valros, A., 2012. Tail biting and production performance in fattening pigs. Livest. Sci. 143, 220-225.

Strappini, A.C., Frankena, K., Metz, J.H.M., Gallo, C., Kemp, B., 2012. Characteristics of bruises in carcasses of cows sourced from farms or from livestock markets Anim. 6, $502-509$.

Sutherland, M. A., Tucker, C.B., 2011. The long and short of it: A review of tail docking in farm animals. Appl. Anim. Behav. Sci. 135, 179-191.

Taylor, N.R., Parker, R.M.A, Mendl, M., Edwards, S.A, Main, D.C.J., 2012. Prevalence of risk factors for tail biting on commercial farms and intervention strategies. Vet. J. 194, 77-83.

Teixeira, D.L., Harley, S., Hanlon, A., O’Connell, N.E., More, S.J., Manzanilla, E.G., Boyle, L.A., 2016. Study on the Association between Tail Lesion Score, Cold Carcass Weight, and Viscera Condemnations in Slaughter Pigs. Front. Vet. Sci. 3, 24.

650 van Staaveren, N., Doyle, B., Manzanilla, E.G., Calderón Díaz, J.A., Hanlon, A. and Boyle, 

of pigs. J. Anim. Sci. 95, 1528 - 1536.

653 Velarde, A., Dalmau, A., Fàbrega, E., and Manteca, X., 2005. Health and welfare 654 management of pigs based on slaughterline records. 56th Annual Meeting of the European Association for Animal Production, Uppsala, Sweden.

657 Velarde, A., Dalmau, A., 2012. Animal welfare assessment at slaughter in Europe: moving 658 from inputs to outputs. Meat Sci. 92, 244-51.

659 Wallgren, P. and Lindahl, E., 1996. The influence of tail biting on performance of fattening pigs. Acta Vet. Scand. 37, 453-460.

661 Welfare Quality®, 2009. Welfare Quality® Assessment Protocol for Pigs. Welfare Quality® 